\title{
La procedencia de la ontología dualista: entre el proyecto de modernidad científica y el neoextracti- vismo
}

The provenance of dualist ontology: between the project of scientific modernity and neo-extractivism

Ramón Sanz Ferramola

Universidad Nacional de San Luis - Argentina

San Luis, Argentina

rsanz@unsl.edu.ar

\section{RESUMEN}

Este trabajo investiga el vínculo histórico-filosófico entre el proyecto que la modernidad epistemológica inaugura hacia principios del Siglo XVII y el neoextractivismo actual. Para ello, el trabajo historiográfico se convierte en búsqueda de la procedencia que, a diferencia de la historia tradicional, se abstiene de reproducir el pasado como mera justificación del presente. Se pretende mostrar la continuidad conceptual y económico-política entre el modo en que la ciencia clásica concibe la relación con la naturaleza devenida objeto y mecanismo, y por lo mismo mercancía. Este modo de pensar y hacer sobre la naturaleza queda sintetizado en la denominada “ontología dualista" en la que la potencia técnica de nuestros días, sin medir consecuencias en su búsqueda de la acumulación del capital, convierte a la propia ciencia-tecnología en fuerza geológica que desbarata el equilibrio bioterritorial entre seres humanos y no humanos, y produce un ecocidio que lleva al cambio climático. Este proceso epistemológico ha sido a la vez un proceso político, y se da en necesidad sincrónica con el colonialismo.

Palabras clave: Modernidad; Ciencia; Colonialismo; Extractivismo; Capitaloceno 


\section{ABSTRACT}

This paper investigates the historical-philosophical link between the project that epistemological modernity inaugurates at the beginning of the 17th century and current neo-extractivism. To this effect, historiographic work becomes a search for provenance, which, unlike traditional history, refrains from reproducing the past as a mere justification of the present. The aim is to show the conceptual and economic-political continuity between the way in which classical science conceives the relationship with nature as an object and mechanism, and therefore as a commodity. This way of thinking and doing about nature is synthesized in the so-called "dualistic ontology" in which the technical power of our days, without measuring consequences in its search for capital accumulation, turns science-technology itself into a geological force that disrupts the bioterritorial balance between humans and non-humans, and produces ecocide that leads to climate change. This epistemological process has been at the same time a political process, and occurs in synchronic necessity with colonialism.

Keywords: Modernity; Science; Colonialism; Extractivism; Capitalocene

\section{Introducción}

Se busca arribar a la procedencia de la Ontología Dualista (Escobar, 2015), materializada en el Capitaloceno y concretada políticamente y económica con el Neoextractivismo (Svampa, 2018). En este contexto, el conocimiento que siempre es producto de las circunstancias del pensamiento, es decir que no hay conocimiento sino geopolítica del conocimiento, fue convertido en conocimiento universal, regulador, canónico y por lo tanto imperial. Lo que había nacido en la cuna de la resistencia emancipatoria se recuesta en el lecho de imposición imperial y funge como detonante de todos los epistemicidios (De Sousa Santos, 2009). Así, queda establecido canónicamente un único modo de vincularse con la naturaleza, un único modo de organizarse socialmente (en torno a la propiedad privada), un único modo de organización económica (capitalismo). Este modo de ser impuesto por un centro que se beneficia de tal imposición constituye la Ontología Dualista, noción propuesta por Arturo Escobar (2015), categoría heredera de la “ontología del centro", propuesta en 1977 por Enrique Dussel (2013).

El Capitaloceno (Haraway, 2016) como actual modelo económico y civilizatorio depredador de la naturaleza, posibilitado por el despliegue tecnológico al servicio del Extractivismo, detonó la constitución de la humanidad como fuerza geológica destructiva y condición de posibilidad de nueva época geológica del Período Cuaternario: el Antropoceno (Trischler, 2017).

Esta situación actual se viene preparando desde hegemonización epistemológica del eficientismo cognoscitivo propuesto por la modernidad y vinculado al optimismo epistemológico en base a la doctrina de la verdad manifiesta, que pretende un absurdo conocimiento absoluto de los procesos naturales para poder apropiarse de la naturaleza. Basta recorrer las páginas de la novela La Nueva Atlántida de Francis Bacon (2015) publicada en 1626, para encontrar expuesto el proyecto de 
modernidad conquistadora de la naturaleza, de los territorios y de la humanidad, que desde 1500 viene siendo perpetrado. Proyecto epistemológico, avalado y puesto en funcionamiento por el despliegue de ejércitos imperiales.

El cogito ergo sum cartesiano comparte esa idea y la convierte en su centro epistemológico, que desencadenará la vía de pensamiento imperial ubicuo, en tanto universalidad construida como discurso de poder, universalidad abstracta o universalismo descarnado, en términos de Aimé Césaire (2006), que encadenará a la mayor parte de la filosofía occidental al poder: modos de colaborar, justificando desde el pretendido ejercicio del libre pensamiento, el despotismo y la arbitrariedad de las naciones poderosas sobre el mundo otro, sistema mundo cogollo del capitalismo.

\section{Metodología}

El discurrir metodológico del trabajo se asienta sobre una mirada diacrónica-crítica, y para ello se remonta el tratamiento historiográfico propuesto por Nietzsche a partir de la noción de genealogía y la consecuente búsqueda de la procedencia, coincidente con una "historia otra", divergente de la historia de los "relatos oficiales".

En el prólogo de La genealogía de la moral, Nietzsche preguntándose por la procedencia del bien y del mal, esa polaridad sobre la que se construye nuestra existencia de seres valorativos, llega a la paradójica conclusión de que el ser humano, en cuyo centro está el conocimiento del mundo, no se conoce realmente a sí mismo: la raíz de tal olvido ancla en la ausencia de la pregunta por sí mismo; si como humanidad no nos hemos buscado, ¿cómo llegará a ser posible que nos encontrásemos? Nietzsche propone el camino de la búsqueda de sí, pero para ello se hace menester dejar de recorrer los senderos de una historiografía repetida y reproducida que siempre llega a la justificación de un presente que obnubila lo acontecido.

De ahí que esta procedencia se ha buscado a partir de una historiografía otra, descentrada de la tradición canónica y pretendidamente universal europea, asentada principalmente en los causes del Pensamiento Decolonial.

\section{Desarrollo}

\subsection{Francis Bacon y la procedencia de la modernidad científica}

En 1626, en La nueva Atlántida, Francis Bacon (2015) describe el proyecto humano que la moderna ciencia propone en las primeras décadas del siglo XVII. El carácter ficcional de la obra está en directo y perfecto vínculo con sus proposiciones filosóficas, que junto con las de Descartes expresan el vuelco moderno en el pensamiento europeo, teniendo como horizonte ontológico y político la transformación del mundo que venía en marcha a partir de 1492 (Dussel, 2007).

En el Prefacio de su Novum organum (publicado originalmente en 1620)-, Bacon (1984) critica duramente dos actitudes filosóficas que poco han contribuido a un conocimiento verdadero. De ahí su primera propuesta: mantenerse prudentemente entre la arrogancia del dogmatismo y la desesperación del escepticismo (o "catalepsia” como prefiere denominarlo). 
El punto de partida baconiano implica purificar la mente de atávicos errores. Es menester un método que posibilite llegar a un conocimiento verdadero, a la ciencia. Para ello, ante todo es necesario romper con antiguos modos de conocer, que para Bacon no son otra cosa que prejuicios a los que da el nombre genérico de "ídolos", que clasifica en las siguientes especies: ídolos de la tribu, ídolos de la caverna, ídolos del foro e ídolos del teatro.

Los ídolos de la tribu son prejuicios arraigados en la misma naturaleza del hombre y en el género humano (de ahí la denominación de “tribu”). Subyace a estos prejuicios la tendencia a antropomorfizar la naturaleza con la consecuente desviación cognoscitiva que ello produce. De este modo, el entendimiento humano se metamorfosea en un "espejo infiel", que muestra una imagen transfigurada y corrupta de la naturaleza. Por su parte, los ídolos de la caverna están relacionados con los errores perceptivos subjetivos (los cuales a su vez son producto de disposiciones subjetivas naturales y culturales), es decir, cada ser humano percibe la naturaleza como si estuviera dentro de una caverna peculiar, única y subjetiva, que hace configurarla erróneamente. En tanto los ídolos del foro tienen que ver con la interacción entre seres humanos a través del lenguaje y la tergiversación que pueden producir las palabras en la tarea por reconstruir racionalmente la naturaleza. Los ídolos del teatro son producto de los diversos sistemas filosóficos y los “malos métodos” de demostración, erróneos, a los que sin embargo la tradición, una fe ciega y la irreflexión han otorgado completa autoridad.

En definitiva, el camino para acceder a la verdad consiste en destituir todos los procesos implicados en el conocimiento que sean causales de mancha en ese espejo inmaculado que es la mente, a fin de reflejar la naturaleza en toda su verdadera dimensión. Este camino de purificación es el que lleva, en el planteo de Bacon, a la ciencia.

Así, el vuelco a la modernidad filosófica que Bacon proyecta implica una transformación de la mirada metafísica a la epistemológica. Tal pasaje se verifica en el predominio del subjetivismo, en tanto análisis de las condiciones del conocimiento que aseguren un saber definitivo e indubitable del mundo exterior. Tal cambio está acompañado por la tendencia a constituir a la razón no solamente como "tribunal supremo", sino como característica suprema del ser humano. Para el pensamiento moderno, la razón se convierte en un fin en sí mismo, con dos características: por una parte, deja de ser substancia para convertirse en función, es decir, conjunto de operaciones mentales con las cuales puede comprenderse y dominarse la naturaleza y la realidad entera; por otra, deja de ser especulación pura para ser entendida ahora como vehiculizadora de conocimiento experimental en tanto restricción causal con ansias de dominación y transformación de la naturaleza.

Pero el fundamento de tal vuelco filosófico moderno se asienta directamente en la doctrina de la verdad manifiesta y su consecuente optimismo epistemológico (Popper, 1994). Según la doctrina de la verdad manifiesta, es posible conocer toda la verdad inscrita en la naturaleza; los seres humanos cuentan con las condiciones necesarias y suficientes para ello. Y si bien el universo es pensado como un laberinto, un acertijo que necesita ser resuelto, el método y orden son condiciones sine qua non para su solución. En un universo pensado como un sistema racional, método y orden racionales son, al que desea conocer, como el hilo para Teseo en el laberinto del Minotauro. 
Bacon parte del supuesto de que es posible el conocimiento absoluto, sin la necesidad de postular ningún rincón escondido a luz natural de la razón. A partir de tal supuesto, toda su formulación epistemológica gira en torno al cómo conocer, es decir, cómo la mente puede acceder al conocimiento de la totalidad de la naturaleza.

Si hay hombres en el mundo que tomen a pecho no atenerse a los descubrimientos antiguos y servirse de ellos, sino ir más allá; no triunfar de un adversario por la dialéctica, sino de la Naturaleza por la industria; no, en fin, tener opiniones hermosas y verosímiles, sino conocimientos ciertos y fecundos, que tales hombres, como verdaderos hijos de la ciencia se unan a nosotros, y abandonen el vestíbulo de la naturaleza en el que solo se ven senderos mil veces practicados, para penetrar finalmente en el interior y el santuario. (Bacon, 1984, p. 29).

En la utopía ficcional de La Nueva Atlantida, Bensalem es la tierra donde la ciencia y la técnica son el eje de la sociedad y de la cultura, razón por la cual han llegado a desarrollos y conquistas inconmensurables. Hacia el final del relato, el director ("padre" se le llama en el relato) de la "Casa de Salomón”, la institución principal “del reino”, dedicada al desarrollo de la ciencia y a la técnica, expresa el sentido del proyecto moderno: "El fin de nuestra fundación es el conocimiento de las causas y movimientos secretos de las cosas, así como la ampliación de los límites del imperio humano para hacer posibles todas las cosas" (Bacon, 2015, p. 60).

Es claro cómo el pensamiento moderno comenzó a desarrollar una nueva relación del hombre con la naturaleza, que Alexandre Koyré (1997) denomina “diálogo experimental”. El intelecto, ahora, se dirige a la naturaleza para interpelarla, para ponerla a prueba.

Producto de tal interpelación es la atribución de un mínimo estatus ontológico: la pura y completa pasividad de la naturaleza. Esta nueva cosmovisión está constituida casi, podríamos decir siguiendo a Prigogine-Stengers (1994), en contra de la naturaleza misma, puesto que le niega la complejidad y el devenir, poniendo en su lugar un mundo eternamente estable y conocible, regido por un pequeño número de leyes sencillas e inmutables.

Surge así la noción de una naturaleza autómata, cuyo comportamiento está regido por leyes accesibles a la razón humana, que a lo largo del siglo XVII quedará pertrechada con los conocimientos adecuados para la instauración de una mecánica racional.

La nueva cosmovisión supone que la naturaleza no es más que un sumiso autómata y, en tal sentido, el proyecto científico se propone develar su ínsita estupidez. La consecuencia inmediata es la ambición de reducir a un puñado de leyes la totalidad de los procesos naturales. De ahí que distintos filósofos modernos se esfuercen por llevar a cabo el programa de constreñir los datos de la experiencia dentro de los constructos racionales que implican los datos empíricos. Aparece entonces el mecanicismo como concepción cosmológica recortada en el horizonte de la cismundanidad (en contraposición a "transmundanidad", en tanto mundo concebido desde su trascendencia), concepción reduccionista según la cual toda realidad es entendida sobre la base de los modelos proporcionados por el mecanismo y la interdependencia entre materia y movimiento local. Si el mecanicismo, además de teoría explicativa, sustenta que lo real es una inmensa máquina, no solamente es una doctrina epistemológica sino ontológica. 
En el mismo sentido, Descartes ofrece un modelo acabado de mecanicismo, dualista en tanto sostiene la irreductible diferencia entre la sustancia pensante, no sometida a las leyes de la mecánica, y la sustancia extensa, totalmente regida por éstas. En este sentido considera que toda la realidad empírica del universo puede y debe explicarse a partir de la mecánica. Así, considera a los animales y al cuerpo humano como meros autómatas, como simples máquinas, reduciendo de este modo biología a mecánica.

Ante tal proyecto epistemológico, tecnológico, ontológico y por eso mismo político (Mignolo, 2010), no es de extrañar que la ciencia y la técnica en la ficticia Bensalem alcance límites insospechados para el siglo XVII, que hoy nos asombran como presagios del proyecto de modernidad científica e industrial, especialmente con la premonición de la transgénesis y la biotecnología de los OGM (Organismos Genéticamente Modificados).

Ficciona Bacon en 1626 en torno a los resultados científicos y tecnológicos a los que ha arribado la "Casa de Salomón":

Realizamos toda clase de injertos, así como hacemos experimentos para convertir los árboles silvestres en frutales; todo esto da lugar a la producción de muchos efectos. En los mismos huertos y jardines conseguimos por medios artificiales que los árboles y las flores florezcan antes o después de su estación correspondiente, y que den fruto con más rapidez que lo harían siguiendo su evolución normal. Logramos también que adquieran un tamaño mayor que el natural, y que su fruto sea mayor y más dulce, y de un gusto, olor, color y forma distintos a los que poseen por naturaleza. Conocemos medios para obtener diversas plantas y desarrollar su crecimiento mediante mezclas de tierras, sin semillas, e igualmente para producir plantas nuevas distintas a las corrientes, y para lograr que un árbol o planta se convierta en otro... Tenemos también parques y recintos con toda clase de animales, a los cuales empleamos no sólo como espectáculo por su rareza sino para disecciones y experimentos... Los hacemos artificialmente más grandes o más altos de lo que es su especie, y al contrario, los empequeñecemos y detenemos su crecimiento; los hacemos más fecundos y fructíferos de lo que es su especie y, al contrario, estériles e incapaces de fecundar (Bacon, 2015, p. 64).

\subsection{El Capitaloceno como realización plena del proyecto de modernidad científica}

Hans Jonas (1995) sostiene que una nueva dimensión ha ingresado en la consideración ética desde mediados del XX. Las nuevas condiciones en que la técnica muestra su poder destructivo con la naturaleza hace que ninguna de las éticas propuestas hasta el momento sean aplicables a tales circunstancias, sobre todo porque las éticas antecedentes solo piensan el pasado y el presente inter-humano, mientras que ahora, con la "heurística del temor" que trae consigo el poder tecnológico de intervención en la naturaleza, es necesario pensar éticamente el futuro y el presente y el pasado de las relaciones inter-humanas en un marco de relaciones de la humanidad con la naturaleza. A partir del siglo XX queda manifiesta la tremenda vulnerabilidad de la naturaleza frente al poder de la intervención técnica de la humanidad y con el nuevo poder técnico de desencadenamiento de series causales, también ha desaparecido la contigüidad espacio temporal de la acción humana y el carácter acumulativo de sus acciones. La técnica, que antes del siglo XX era un medio en grado finito (por ejemplo, para la adquisición de bienestar y 
confort), se ha potenciado hasta hacer posible el proyecto de dominación sobre la naturaleza que Francis Bacon proyectaba en las postrimerías del siglo XVII: un impulso infinito de dominación en términos de progreso. Es el "triunfo del homo faber sobre el homo sapiens", lo cual implica una transformación íntima del ser humano, y por eso la tecnología cobra significación ética. La frontera entre el Estado y la Naturaleza se ha disuelto, y con ella la frontera entre lo artificial y lo natural. Aparece entonces un imperativo moral de protección en su vulnerabilidad al mundo físico. El imperativo categórico kantiano que originalmente tenía aplicación intersubjetiva, se ha reconvertido: el nuevo imperativo del homo faber se dirige más a la política pública que al comportamiento privado. "No pongas en peligro las condiciones de continuidad indefinida de la humanidad en la tierra" o "Incluye en tu acción presente como objeto también de tu querer la futura integridad del ser humano". De ahí que, "la esencia modificada de la acción humana modifica la esencia básica de la política”. (Jonas 1995, p. 37)

La formulación teórica del triunfo del homo faber por sobre el homo sapiens, y el consecuente llamado a una ética de la resposabilidad que propone Jonas, adquirió evidencia científica a partir del concepto de Antropoceno, que tiene un origen eminentemente científico en tanto concepto propio de la geología, y que luego adquirió la dimensión de un concepto cultural en un sentido más amplio.

La idea central del Antropoceno es que los seres humanos con su poder tecnológico, se han convertido en una fuerza geológica poderosa, tanto, que es necesario designar una nueva época geológica para describir con precisión este desarrollo actual de la geología (el Antropoceno como Época Geológica se agrega al Pleistoceno y al Holoceno, dentro del Período Cuaternario en la Era Cenozoica). Según la formulación original de Crutzen, esta nueva "época de los seres humanos”, el Antropoceno, comenzó con la Revolución industrial a finales del siglo XVIII. La evidencia que apoya la datación del inicio del Antropoceno fue producto de la innovación tecnológica. Tres procesos principales trabajaron juntos: la mecanización de la mano de obra; la producción a gran escala y la transformación de la energía creada por la máquina de vapor y la explotación intensiva y extensiva, la producción y el uso del carbón y el hierro.

A partir de esta formulación originaria del Antropoceno, han aparecido dos nuevas hipótesis respecto del momento histórico de su origen. En 2015 los científicos británicos Simon Lewis y Mark Maslin (2015) propusieron que la fecha de comienzo del Antropoceno debería retroceder hasta principios del siglo XVII, bajo la argumentación de que las consecuencias de la colonización de América estaba ya tan extendida mundialmente, que un efecto global podría ser identificado, incluso antes de la Revolución Industrial: la caída dramática en la población debido a la conquista colonial del mundo por parte de Europa, significó que grandes extensiones de tierra quedaran sin cultivar y se convirtieran en selva; este aumento de vegetación alcanzó su punto máximo en 1610, y este efecto dejó un rastro marcado en el registro geológico en forma de un descenso en la concentración de dióxido de carbono atmosférico. Esta hipótesis es severamente cuestionada por muchos geólogos, en tanto niegan que un impacto de ese tipo, relativamente pequeño (a escala geológica), sirva como un marcador geológico del comienzo del Antropoceno.

La tercera datación propuesta remite a la denominada "gran aceleración" a mediados del siglo $X X$. Como ha demostrado un equipo internacional de investigadores climáticos y del sistema Tierra - Earth system scientists - encabezado por Will Steffen, durante el transcurso de la década 
de 1950 las curvas de numerosos parámetros cambiaron de una forma lineal a un crecimiento exponencial. Esta curva de medición se presenta a escala global en fenómenos como el uso de recursos (petróleo crudo, agua y fertilizantes artificiales), así como la construcción de presas, vehículos, teléfonos y restaurantes McDonald's, e indicadores económicos, por ejemplo, el aumento del turismo internacional y las inversiones extranjeras y el producto nacional bruto de los países más poderosos del planeta. El rápido incremento en el consumo de energía, junto con la motorización masiva de grandes partes del mundo, fue de la mano con el desarrollo de la sociedad de consumo, que se basa en una corriente interminable de innovaciones tecnológicas (Trischeler 2017).

El Anthropocene Working Group del Servicio Geológico Británico, integrado por un grupo bajo la dirección de Jan Zalaslewicz, sostiene la misma datación del origen del Antropoceno, pero por razones distintas: el planeta habría atravesado el umbral de una nueva época geológica hacia 1950, y la prueba ofrecida son las marcas estratigráficas que determina ese cambio, son los residuos radiactivos del plutonio, tras los numerosos ensayos con bombas atómicas realizados a mediados del Siglo XX (Svampa 2018).

La ciencia geológica actual, entonces, debate acerca de la datación de Antropoceno, pero parece haber un consenso generalizado acerca de la necesidad de inclusión de una nueva Época Geológica caracterizada por el poder técnico humano, capaz de incidir sobre los procesos naturales.

Pero, el Antropoceno también ha adquirido una dimensión política y ética, para referirnos a la peculiar etapa histórica que estamos viviendo. Para Donna Haraway (2016), hablar del Antropoceno significa hablar de una época geológica que trágicamente ha reemplazado al Holoceno, que se caracterizaba por ser un período en el que existían abundantes áreas de refugio en las cuales los diversos organismos podían sobrevivir ante condiciones desfavorables, pudiendo sostener una repoblación cultural y biológica rica y diversa. De ahí que el Antropoceno sea el período de la destrucción de espacios y tiempos de refugio para las personas y para los otros seres vivientes. Por eso nuestro tiempo está caracterizado por la existencia de refugiados: la tierra está llena de seres humanos y no humanos que buscan refugios, que la propia humanidad ha eliminado.

Otro de los autores que ha trabajado en este sentido es el historiador ecomarxista Jason Moore. Según su postura, el Antropoceno, implica -además de un concepto propio de las ciencias geológicas- también una reconfiguración de la historia de la humanidad (Moore 2016). Pero, aceptar esta denominación (“Antropoceno”) implicaría caer en la trampa de un viejo truco del capitalismo: decir que los problemas del mundo son creados por toda la humanidad, cuando en realidad han sido creados por el capitalismo, y en este sentido, para escapar de la trampa, nuestro autor prefiere hablar Capitaloceno. En efecto, en la época que va desde 1450 a 1750 vemos una revolución en la producción del medio ambiente sin precedentes desde la revolución neolítica con la aparición de las primeras ciudades. Esta revolución estuvo marcada, e incrementada en cantidad y calidad de efectos y velocidad de producción, por el cambio ambiental que emanó del capitalismo atlántico-céntrico. Una transformación de paisajes y ambientes muy rápida que afectó a todo el planeta, región tras región. En estos siglos se ve la dominancia de producción e intercambio de mercancías en la transformación del ambiente global, y especialmente en nuevas formas de entender la naturaleza como recursos para el desarrollo económico. Entre 
1450 y 1750 se produjo una inversión de un mecanismo que había durado miles de años: en las civilizaciones precapitalistas el crecimiento de la población iba sucedido de una expansión de asentamientos a la que seguían el comercio, los mercados y el intercambio y producción de bienes. A partir del siglo XVI ocurrió lo contrario, en vez de desplazarse la población, fueron las mercancías las que cambiaron de sitio primero y la población las siguió (Wedekind y Milanez, 2017). De allí la importancia de las fronteras agrícolas y mineras, las denominadas "fronteras de la modernidad", que son los imputs desde donde se irradia poder económico a los centros industriales y financieros globales, a la vez que deterioro ambiental y pobreza (Tiapa, 2018).

Bruno Latour (2017) establece un interesante paralelismo entre el actual debate sobre el papel de los seres humanos como una fuerza geológica y la controversia sobre el estatus de los seres humanos en el universo, que propuso Galileo Galilei en el Siglo XVII: cuando presentó la tesis de que la Tierra se movía alrededor del Sol, y con ello cuestionó la concepción establecida del mundo, atrajo la atención de la Inquisición. La tesis del Antropoceno no es que "la Tierra se está moviendo", sino más bien que "la Tierra se mueve gracias a la intervención e injerencia humana”. Esta tesis también convoca a la actual Inquisición constituida por la fuerza del pensamiento hegemónico, que Latour identifica sobre todo con esos círculos en la política y la industria que niegan que los seres humanos son la causa del cambio climático.

\footnotetext{
Desde la década de 1990, lo sabemos, poderosos grupos de presión se han movilizado para sembrar dudas sobre los "hechos" que comenzaban a tener consenso dentro de las comunidades de investigadores sobre el origen humano de las mutaciones climáticas. A pesar de la distinción entre hechos y valores, tan cara a los filósofos y a los éticos, los patrones de las grandes empresas amenazadas entrevieron de inmediato lo que estaba en juego. Notaron que, si se comprobaban los hechos -el origen fundamental de las mutaciones climáticas serían las emisiones de dióxido de carbono-, los políticos movilizados por la inquietud del público, iban a exigir que se tomaran medidas de inmediato. (Latour, 2017, p. 39)
}

\subsection{La ontología dualista del capitalismo y el colonialismo extractivista}

Este proyecto de modernidad científica que vemos emerger de los planteos baconianos, y concretarse trágicamente en nuestros tiempos de Capitaloceno, tiene un completo correlato en la emergencia de la modernidad económico-política del capitalismo. La naturaleza devenida mercancía, adecuada a las estrategias productivas de la nueva centralidad europea, es incorporada a los procesos de acumulación del capital.

El pasaje del proyecto modernidad-científica a la modernidad-política no puede entenderse sin analizar el modo en que una perspectiva epistemológica deviene y se corporiza en una perspectiva ontológica capaz de sustentar discursivamente acciones políticas, y convertirse en razón de Estado.

Arturo Escobar (2015) ha denominado a este régimen tecno-capitalista de la naturaleza como “Ontología dualista”, en donde el espacio construido desde la visión euclideana, baconianacartesiana y estática, a manera del espacio absoluto, universal, sin huella humana, puede ser apropiado sin mediar consideraciones éticas. Separa lo humano y lo no humano, la naturaleza 
y la cultura, el individuo y la comunidad, "nosotros" y "ellos", mente y cuerpo, lo secular y lo sagrado, razón y emoción, arrogándose el derecho de ser "el” mundo civilizado, libre, racional, en donde no tiene ningún lugar ningún otro mundo humano que esté concebido a partir de la continuidad naturaleza-humanidad.

Desde esta perspectiva fue integrada nuestra Abya Yala, como luego África, en el mercado mundial como suministradora de recursos primarios a partir de 1492. De esta región salió el oro, la plata y las piedras preciosas que financiarían la expansión del imperio español, pero, sobre todo, el surgimiento del capitalismo en la Europa central. Esta es la riqueza hizo bascular el centro del sistema mundial de Asia (que tenía su propia crisis interna, en particular la China) a Europa (Dussel, 2007). Y desde entonces estas tierras americanas, asumieron una posición sumisa en el contexto internacional al especializarse en extraer recursos naturales para el mercado mundial.

En este sentido, es importante pensar el colonialismo como una continuidad histórica de nuestra existencia como pueblos, y como individuos, puesto que de lo contrario perderíamos el horizonte desde donde situar nuestro presente y su necesaria proyección. Para ello retomamos la periodización que propone Eugenio Zafaroni (2015) entre colonialismo originario, neocolonialismo y fase superior del colonialismo. El colonialismo originario duró mientras persistió el sistema de producción esclavócrata, en el que desembozadamente el sistema económico se sustentaba en la total negación de derechos a los seres humanos (esclavos y esclavas, indios e indias encomendados, etc.). El neocolonialismo, se caracterizó por el control de nuestros países por medio de las minorías terratenientes.

La fase superior del colonialismo está vinculada a las nuevas condiciones geopolíticas que modelan el mundo a fines del siglo XX. Francis Fukuyama (1989), a menos de un año de la Caída del Muro de Berlín, anunciaba triunfal el fin de la historia en el sentido del inicio de una etapa en la que la ideología muerta del socialismo, da paso a un "Estado universal homogéneo", que hace imposible distintos modelos socio-económico-políticos por la "impertérrita victoria del liberalismo económico y político". En tal lugar histórico podríamos situar el origen próximo de nuestro actual contexto geopolítico latinoamericano en relación con los países del Primer Mundo.

David Harvey (2004), propone que el modo en que el capitalismo actual, desde la caída del Muro, se da a través de las empresas multinacionales y los estados cómplices que actúan hoy en territorios del tercer mundo, en base a lo que él denomina “acumulación por desposesión”. En la acumulación por desposesión cobra más vigencia que nunca la perspectiva teórica geopolítica (denunciada originalmente por las denominadas Teorías Latinoamericanas de la Dependencia de la década de 1960 (Borón, 2008)) del centro que acumula y la periferia que es víctima de desposesión, cuyas consecuencias nefastas son la expropiación económica, la destrucción de territorios y la depredación de pueblos y ambientes. Esta acumulación por desposesión, fue preparada en la década de 1990 en que se da un período caracterizado por el asentamiento de las bases del Estado Meta-Regulador (Svampa, 2011), definido por la instauración del marco jurídico que garantiza la institucionalización de los derechos de las grandes corporaciones y la aceptación por parte de los Estados nacionales de normativa creada en los espacios transnacionales (Banco Mundial, Fondo Monetario Internacional, etc.). Este marco legal propuso e impulsó la reprimarización de una economía altamente dependiente de los mercados externos, así como 
propició la imbricación -en distintos grados, desde la institucionalidad hasta la más lisa y llana corrupción- de los Estados Nacionales, Provinciales y Municipales con los grupos económicos privados. Mal fruto de la acumulación por desposesión son la megaminería a cielo abierto, la privatización de grandes territorios, el fomento estatal de la destrucción del bosque nativo para la ampliación de la frontera agroindustrial, y a nivel regional los proyectos previstos por la IIRSA (Iniciativa por la Integración de la Infraestructura Regional Sudamericana). Esta caracterización de las políticas llevadas a cabo en nuestra región son clara muestra de una más profunda división territorial y global del trabajo entre el Norte y el Sur: este produce materia prima a bajo costo monetario y alta depredación ambiental y social, aquel se beneficia y enriquece aún más gracias a su desarrollo tecnológico y el consecuente valor agregado, por la elaboración de la materia prima aquí extraída.

Existimos, pues, en presencia de una nueva lógica neoliberal, en la que el mercado en cuanto tal ha sido substituido por la vinculación entre el capital financiero respaldado por un poder estatal cómplice, en donde si el poder del mercado no alcanza para lograr determinados objetivos mercantiles, está disponible el poder militar. Una alianza desembozada entre los estados colonizadores y los aspectos depredadores del capital financiero es lo que caracteriza la acumulación por desposesión, un capitalismo de rapiña, en el cual se da una expoliación o acumulación de recursos sin límite (lo cual es contradictorio con las leyes fundamentales de la biología y la física); un capitalismo dedicado más a la apropiación y devaluación de activos que a su construcción a través de inversiones productivas (Alier y Wagensberg, 2017).

De ahí la necesidad de una referencia obligada al Extractivismo, que es una categoría analítica nacida en Latinoamérica, con gran potencia descriptiva y explicativa y un alto poder denunciativo, que alude a patrones de desarrollo insustentable y advierte sobre la lógica actual del capitalismo de acumulación por desposesión; por lo tanto es más un modo de apropiación más que de producción, apropiación de la naturaleza devenida recurso natural, en grandes volúmenes, en general sin procesamiento, para su exportación (Svampa, 2019). Sin embargo, no debe olvidarse que el extractivismo es un rasgo estructural del capitalismo originario desde 1500 como economía-mundo, a partir de la diferenciación y jerarquización de territorios entre las metrópolis imperiales y las colonias: saqueo y expoliación de las colonias para el aprovisionamiento de las metrópolis. Potosí marcó un modo de apropiación de la naturaleza a gran escala, que implicó el genocidio de millones de personas trabajadoras esclavizadas de la mina (Machado Araoz, 2018).

El extractivismo ha ido cambiando al compás del desarrollo de tecnologías extractivas (lixiviación, fracking, etc), siempre guiado por el ideal baconiano del proyecto de la modernidad científica. En la actualidad hablamos de extractivismo de tercera y cuarta generación, caracterizado por el uso intensivo del agua y la energía y recursos extractivos de alta tecnología (modalidad de extractivismo actual). Históricamente los territorios colonizados primero y extractivizados después, han sido cotos de destrucción y saqueo; estos territorios se fueron configurando al calor de los ciclos económicos impuestos por la lógica capitalista a través de una expansión de las fronteras de la mercancía, proceso que trajo como consecuencia, a la vez que una enorme rentabilidad para los agentes extractivistas, un profundo proceso de pauperización para los y las extractivizados (territorios y personas). El extractivismo del siglo XXI es el neoestractivismo, que es continuidad del extractivismo histórico pero que tiene como característica diferencial, la 
aparición de una fuerte presión sobre los bienes naturales y los territorios, acompañada de una vertiginosa expansión de la frontera de los commodities.

Las condiciones de posibilidad de tal contexto, ponemos situarla en la emergencia de lo que Boaventura de Sousa Santos (2006) denomina "fascismo societal", que no se trata de una vuelta al Fascismo de los años 1930 y 40, no es un régimen político sino más bien un régimen social, y casi podría decirse que es el modo en que la democracia se ha corrompido en nuestros días, un totalitarismo con mecanismos de disciplinamiento democrático. Dentro de sus herramientas más preciadas, que vemos utilizar en nuestros territorios con más asiduidad de la que desearíamos, están, por un lado, el "fascismo del estado paralelo" constituido por aquellas formas de acción estatal que se caracterizan por su distanciamiento del derecho positivo cuando ello sea conveniente; el Estado actúa, según la circunstancia, con el derecho o con un régimen de excepcionalidad donde las garantías constitucionales y legales no existen, según se aplique en "lugares" de civilización o en "lugares" de barbarie. Por otro, el "fascismo paraestatal-territorial”, resultante de la usurpación por parte de multinacionales (poderosos actores sociales) de las prerrogativas estatales de la coerción y la regulación social en un territorio dado, cooptando u ocupando las instituciones estatales para ejercer regulación social sobre los habitantes del territorio. Se trata de territorios colonizados en manos de las empresas, en tanto el Estado pareciera cederlos a estas instancias privadas, que actúan en ellos con completo permiso estatal.

En la periferia que habitamos, en esta fase superior del colonialismo, se opera tratando de imponer gobernantes sumisos a los intereses del capital financiero transnacional o procurando destituir a quienes les opongan resistencia o descalificar a los políticos que los denuncian. Para eso el colonialismo se vale de la opinión pública, convenientemente formateada por los medios masivos de comunicación monopolizados, que forman parte del mismo capital transnacionalizado, como también de políticos inescrupulosos o insensatos, de lobbystas (corruptores especializados) y de técnicos políticamente asépticos, previamente esterilizados en los cónclaves de sus Think Tanks centrales.

En el sistema mundo actual, la disputa entre aquellos modelos estatales que buscan una redistribución que reduzca la distancia entre las capas sociales y aquellos que buscan concentrar la riqueza y desposeer a las mayorías es uno de los temas centrales de la agenda mundial: se trata de la disputa entre un modelo incluyente y otro excluyente. Pero también se trata de una disputa entre ontologías: la dualista vs. la relacional.

\section{Conclusión}

Puede reconocerse una línea proyectual entre la modernidad científica plasmada en el Novum Organum y La Nueva Atlántida de Francis Bacon, publicados en 1620 y 1626 respectivamente, y el Capitaloceno. Esta continuidad puede pensarse como la continuidad de la ontología dualista, universalizada como prototipo e impuesta como canon. El anhelo de poder y transformación sobre la naturaleza para convertirla en un objeto capaz de producir riqueza infinita y única vía del progreso humano que estaba presente en los albores del siglo XVII se consuma en la potencia técnica que, sin medir consecuencias en su búsqueda de la acumulación del capital, convierte a la propia ciencia-tecnología en fuerza geológica que desbarata el equilibrio bioterritotorial del 
planeta y produce un ecocidio que lleva al cambio climático. Este proceso epistemológico se da en necesidad sincrónica con el colonialismo.

En esta matriz epistemológica y política, el extractivismo, desde 1492 hasta el neoextractivismo actual, fue y es la forma en que el capitalismo acumula a través de la desposesión, reproduciendo y la agravando las desigualdades de un sistema mundo constituido de centro(s) y periferias.

Frente a la ontología dualista siempre ha estado presente, pero silenciada con métodos más o menos violentos la ontología relacional (Escobar, 2015), oculta pero viviente en la resistencia de las culturas y los pueblos subalternizados.

Remontar la procedencia de tal ontología relacional será objeto de otro trabajo.

\section{REFERENCIAS}

Alier, J. \& Wagensberg. J. (2017). Solo tenemos un planeta. Sobre la armonía de los humanos con la naturaleza. Icaria editorial

Bacon, F. (1984). Novum organum. Sarpe.

Bacon, F. (2015). La nueva Atántida. Luarna Ediciones.

Borón, A. (2008). Teoría(s) de la Dependencia. Realidad Económica, 238.

Césaire, A. (2006). Discurso sobre el colonialismo. Akal

De Sousa Santos, B. (2006). Reinventar la democracia. Reinventar el estado. CLACSO

Dussel, E. (2013). Filosofía de la liberación. Editorial Docencia.

Dussel, E. (2007). Política de la liberación. Historia mundial y crítica. Editorial Trotta.

Escobar, A. (2015). Territorios de diferencia: la ontología política de los "derechos al territorio". Cuadernos de Antropología Social, (41), 25-38. https://doi.org/10.34096/cas.i41.1594

Fukuyama, F. (1989). The end of History? The National Interest, 16, 3-18.

Haraway, D. (2016). Antropoceno, Capitaloceno, Plantacionoceno, Chthuluceno: generando relaciones de parentesco. Revista Latinoamericana de Estudios Críticos Animales, 3(1), 15-26. http://revistaleca.org/ journal/index.php/RLECA/article/view/53/o

Harvey, D. (2004). El "nuevo" imperialismo: acumulación por desposesión. Socialist Register, 99-129. https://socialistregister.com/index.php/srv/article/view/14997

Jonas, H., (1995). El principio de responsabilidad. Ensayo de una ética para la civilización tecnológica. Editorial Herder.

Koyré, A. (1997). Estudios de historia del pensamiento científico. Siglo XXI Editores.

Latour, B. (2017). Cara a cara con el planeta: Una nueva mirada sobre el cambio climático alejada de las posiciones apocalípticas. Siglo XXI Editores.

Lewis, S. \& Maslin, M. (2015). Defining the Anthropocene. Nature, 519(2)128-146. https://doi.org/10.1038/ nature 14258

Machado Aráoz, H. (2018). Potosí el origen. Genealogía de la minería contemporánea. PDTG-Derechos Humanos sin Fronteras.

Mignolo, W. (2010). Desobediencia epistémica: retórica de la modernidad, lógica de la colonialidad, gramática de la descolonialidad. Del Signo.

Moore, J. (2016). Anthropocene or Capitalocene? Nature, History, and the Crisis of Capitalism. KAIROS-PM Press, 
Popper, K. (1994). Conjeturas y refutaciones. El desarrollo del conocimiento científico. Paidós.

Prigogine, I., \& Stengers, I. (1994). La nueva alianza. Alianza Editorial.

Svampa, M. (2011) Modelos de desarrollo, cuestión ambiental y giro eco-territorial. En H. Alimonda, (Coord.). La naturaleza colonizada. Ecología política y minería en América Latina. (pp. 181-218). CLACSO.

Svampa,M.(2018). Imágenes del fin. Narrativas de la crisis socioecológica en el Antropoceno. Nueva Sociedad, 278, 151-164. https://nuso.org/articulo/svampa-crisis-ecologica-antropoceno-calentamiento-global/

Svampa, M. (2019). Las fronteras del neoextractivismo en América Latina. Conflictos socioambientales, giro ecoterritorial y nuevas dependencias. Universidad de Guadalajara-Bielefeld University Press.

Tiapa, F. (2018). Alteridades geopolíticas y construcción de conocimiento en las fronteras de la Modernidad. Revista Antropologías del Sur, 5(10), 167-187.

Trischler, H. (2017). El Antropoceno, ¿un concepto geológico o cultural, o ambos? Desacatos, 54, 40-57.

Wedekind, J. \& Milanez,F.(2017). Entrevista a Jason Moore: Del Capitaloceno a una nueva política ontológica. Revista Ecología Política, 53, 108-110. https://dialnet.unirioja.es/servlet/articulo?codigo=6063843

Zafaroni, E. (2015). El derecho latinoamericano en la fase superior del colonialismo. Passagens. Revista Internacional de História Política e Cultura Jurídica, Rio de Janeiro. 7(2), 182-243. https://doi. org/10.15175/1984-2503-20157201

\section{AUTOR}

Ramón Sanz Ferramola. Doctor en Filosofía por la Universidad Nacional de Cuyo (2007) y postdoctor en Ciencias Sociales por la Universidad Nacional de Córdoba (2017) (ambas de Argentina). Docente de grado y posgrado. Director del Doctorado en Educación de la Facultad de Ciencias Humanas de la Universidad Nacional de San Luis. Investigador, director del Proyecto de Investigación "Ética, bioética y derechos humanos en el sur global” (CyT-UNSL). Coordinador de la Cátedra Libre de Soberanía Alimentaria y Bioética del Sur de la Universidad Nacional de San Luis.

\section{Conflicto de intereses}

El autor declara que no existe conflicto de interés posible.

\section{Financiamiento}

No existió asistencia financiera de partes externas al presente artículo.

\section{Agradecimientos}

$\mathrm{N} / \mathrm{A}$ 